\title{
Closing a Front Door to Homelessness among Veterans
}

\author{
James McGuire
}

Received: 15 March 2007/ Accepted: 22 March 2007/Published online: 5 June 2007

(C) Springer Science+Business Media, LLC 2007

\begin{abstract}
The U.S. Department of Veterans Affairs (VA) has been identified as a mainstream institution to help prevent homelessness among America's veterans. The large numbers of incarcerated veterans with serious mental illnesses and substance abuse disorders who are at risk for homelessness support the need for expanded VA outreach to this population. Since 2002, the VA has contacted almost 6,500 veterans in prison or jail. Its leadership role in affording comprehensive health, mental health, social resources, corrections outreach, and current policy and planning strategies positions the VA to provide system wide service to veterans leaving correctional institutions. As this VA outreach program proceeds, examining the links among program assumptions, veteran needs and outcomes, and existing evaluation processes can help to maintain focus on homelessness prevention strategies.
\end{abstract}

Keywords Homelessness - Prevention - Incarcerated veterans · Serious mental illness

\section{Introduction}

In ' A Plan: Not a Dream-How to End Homelessness in Ten Years,' the National Alliance to End Homelessness (2000) drew attention to the limitations of a homeless

J. McGuire

Department of Veterans Affairs Northeast Program Evaluation Center (NEPEC), Los Angeles, USA

J. McGuire

UCLA School of Public Policy and Social Research, Los Angeles, USA

\section{J. McGuire ( $\bowtie)$}

Homelessness Prevention and Incarcerated Veterans Programs (10H-5), VA West Los Angeles Healthcare Center, Building 206, Room 109, 11030 Wilshire Blvd., Los Angeles, CA 90073, USA e-mail: James.McGuire@va.gov 
assistance system that ended homelessness for 1000s of people every day while others quickly replaced them. The Plan called for 'closing the front door' to homelessness by holding mainstream programs "more accountable for the outcomes of their most vulnerable clients and wards"' (p. 10). Veterans' benefits, medical centers, and employment programs were prominently identified among mainstream programs and providers as those needing to be counted on to help prevent veterans from becoming homeless.

Reference to the benefits and services provided by the U.S. Department of Veteran Affairs (VA) reflects the well-known and long-established reality found in a 1996 survey of homeless people in America that indicated that veterans were 33\% of the adult male homeless population (Burt et al. 1999). Although this represented a small decline from the estimated percentage of homeless veterans in the 1980s, veterans were still at higher risk for homelessness than non-veteran adult males (Gamache et al. 2001).

The VA's Health Care for Homeless Veterans (HCHV) program was developed in the 1980s to engage homeless veterans through community-based outreach in an array of VA services: pension and compensation benefits; medical and surgical inpatient and outpatient treatment including primary care prevention and specialty care services; outpatient and inpatient mental health and substance abuse services; and vocational and residential services (U.S. Department of Veterans Affairs Office of Public Affairs 2006). With some exceptions, HCHV programs provide outreach and residential rehabilitation services to homeless veterans who meet the McKinney Act definition of homelessness. However, the McKinney Act definition excludes imprisoned individuals. In an unrelated action in 1999, Congress excluded from the VA medical benefits package "(h)ospital and outpatient care for a veteran who is either a patient or inmate in an institution of another government agency if that agency has a duty to give the care or services', (Title 38 CFR section 17.38).

A U.S. Department of Justice Bureau of Justice Statistics (BJS) report found that $12 \%$ of all inmates in U.S. correctional institutions were veterans, many with significant homelessness, mental health, employment, and substance abuse problems (Mumola 2000). The study estimated that $80 \%$ of these veterans had military discharges that made them eligible for VA services upon release. In light of a report by the Re-entry Policy Council of the Council of State Governments (2005) stating that 680,000 prison and 7.5 million jail inmates are released annually back to their communities, large numbers of these veterans could be expected to be released and returned to community life after serving their sentences.

Homelessness prevention advocates view the discharge of inmates to communities without further institutional commitment or support a 'front door' failure of mainstream programs (National Alliance to End Homelessness 2000). They point to $50 \%$ re-incarceration rates (Langan and Levin 2002) as a reason to undertake prevention strategies directed to the inmate re-entry process. To ensure efficiency of such efforts, Burt and Pearson (2005) recommend that homelessness prevention initiatives (a) target services to those at highest risk for becoming homeless without intervention and (b) collect and examine outcomes of prevention activities.

In 2004, the VA launched a series of actions that together substantially increased the agency's prevention efforts on behalf of incarcerated veterans preparing for 
release to the community. Most of these veterans have serious mental illnesses and/ or substance abuse disorders. This paper describes and assesses the VA's incarcerated veteran initiative and examines this effort from a homelessness prevention perspective, encompassing issues of risk, prevention strategy, and evaluation.

\section{Homelessness Risk among Incarcerated Veterans}

Considering the attention that the relationship between incarceration and homelessness has received, it is surprising how little research exists that looks at inmates re-entering communities and the subsequent rates of homelessness. The only published work on this subject examined the post-prison experience of released New York State prison inmates, finding that $11.4 \%$ had a homeless shelter episode within 2 years of release (Metraux and Culhane 2004). Other studies have documented the legal and homelessness status of either parole or homeless populations. For example, the California Department of Corrections reported that up to $10 \%$ of the state's parolees were homeless (California Department of Corrections 1997), and a Baltimore study indicated that one-half of people sleeping on the streets have a history of incarceration (Fischer 1988). In general, researchers who study homeless people have found that prior incarceration, particularly for males, is an important risk factor associated with homelessness (Burt 2001).

Homeless veterans essentially have the same homelessness risk factors as other homeless Americans: poverty, joblessness, mental illness, and substance abuse (Rosenheck and Koegel 1993). Within age and service era cohorts, younger veterans and veterans of the post-Vietnam All Volunteer Force era have a higher risk of homelessness compared to other veterans. Yet less than one-third of veterans in one study reported that military service increased their risk for homelessness (Mares and Rosenheck 2004).

Rates of criminal involvement by homeless veterans are also similar to rates of non-veterans. In describing special populations of homeless Americans, Rosenheck et al. (1999) note the special national concern afforded homeless veterans, yet point out that boundaries between homelessness and criminal justice status among veterans are not as clear as the public might think. In one sample of 10,000 veterans seen in a national VA program, one-third of whom had served in combat, over $50 \%$ had significant criminal histories. Studies which capture data on legal status, and have included or focused on veterans, have found the following types of criminal justice involvement to be associated with homelessness: (a) history of arrests (Caton et al. 2005); (b) having been jailed (Rosenheck and Koegel 1993); and (c) criminal behavior (Douyon et al. 1998). Duration of homelessness was associated with criminal history in one of two samples of veterans surveyed in a VA Domiciliary program (Wenzel et al. 1993).

It is beyond the scope of this paper to estimate increased likelihood of homelessness for veterans who have criminal histories, mental illness, or other significant risk factors, or to determine the risk of homelessness for veterans released from jail or prison. Community studies of risk do place veterans, in 
particular those with serious mental illness or substance abuse disorders, well within the mainstream of those at risk for homelessness as well as at increased risk for criminal justice involvement. Viewed from the institutional perspective, the Mumola (2000) study of incarcerated veterans documented a cluster of factors that suggest substantial risk for homelessness at the point of their re-entry to the community. Prior to incarceration, $81 \%$ reported drug use problems; $31 \%$ in prison (35\% in jail) reported CAGE-assessed current alcohol dependency; $19 \%$ in prison (25\% in jail) had been identified as mentally ill during incarceration; and $12 \%$ in prison ( $23 \%$ in jail) had been homeless for some period during the 12 months before incarceration.

\section{VA's Prevention Strategy}

\section{Background}

VA and non-VA policy experts have promoted homelessness prevention strategies since the early 1990s (Lezak and Edgar 1996; Lindblom 1991). Prevention efforts specifically directed to incarcerated veterans can be traced back to the 1980s when a small number of VA clinicians from outpatient mental health, substance abuse, and post traumatic stress disorder treatment clinics at a few VA Medical Centers (VAMCs) pioneered the provision of services to incarcerated veterans re-entering their communities. In the late 1990s, VA's HCHV program staff also began conducting outreach to some veterans in prisons and jails, in part because of the relationship between incarceration and homelessness, and in part because of VA's campaign to broaden its veteran enrollment base.

These initiatives drew upon a model (McGuire et al. 2003) developed for outreach to homeless veterans in the community that included: making contact and building credibility; engaging clients; identifying mental illness, substance abuse, housing and employment needs through assessment; and provision of ongoing case management after release. Outreach workers were masters level social workers, paraprofessional social workers or addictions staff, or nursing staff whose follow-up responsibilities were to link veterans to needed medical, psychiatric, substance abuse, and/or social services, that included housing and employment.

Contacting incarcerated veterans also built on a VA tradition of viewing mental health and substance abuse issues that resulted in incarceration as being related to experiences encountered while in the military. VA clinical staff who were veterans themselves had a particularly strong commitment to provide mental health and substance abuse services to their fellow veterans.

By 2000, an informal review of the VA's 22 Veteran Integrated Service Networks (VHA's regional entities called 'VISNs') found that 20 conducted some form of outreach, health, or benefit service directed to re-entering veterans. Since Fiscal Year 2002 when the VHA's Northeast Program Evaluation Center began tracking data on jails or prisons as locations of outreach activities, 6,493 veterans had received outreach services while incarcerated-not an insubstantial number (Kasprow et al. 2003, 2004, 2005, 2006). 
Early prevention outreach efforts by individual VA clinicians and some VAMCs were augmented in 2003 by a U.S. Department of Labor (DOL)-VA program named the Incarcerated Veterans Transition Program (IVTP). With leadership on the VA side from the Director of VA's Homeless Programs, IVTP is a seven site DOL funded pilot project mandated by Congress under Public Law 107-95 (Homeless Veterans Comprehensive Assistance Act, 2001) to carry out a demonstration program to provide services to assist eligible veterans in transition from institutional living, including jails and prisons. As the lead agency, DOL's role has been to provide employment services to incarcerated veterans making the transition to community living. The role of the VA in IVTP has been to assist with access to VA benefits and healthcare, including VA-funded transitional housing. By the end of its second year in 2006, IVTP has provided employment services to 1,448 incarcerated veterans. IVTP staff also coordinate with VA outreach staff to link veterans to VA healthcare and/or benefits either directly or through referral.

VA has learned four important lessons from these beginning efforts. First, a collaborative partnership with the corrections system must be established and nurtured over time to gain access to veterans and to insure coordination of re-entry planning. Second, practical planning to assure that veterans leaving prison or jail are actually connected to the VA for follow-up services is essential. Without such arrangements in place, barriers (lack of transportation, money) at the time of release may prevent follow-through by the veterans. Third, an array of both VA and nonVA community services is needed to provide the scope and intensity of services needed by re-entering veterans. Finally, veterans who have been incarcerated for long periods, usually in prison, benefit from an extended process of deinstitutionalization upon release during which considerable structure is initially provided that is gradually replaced by personal initiative; new coping skills are also developed to support adaptation to community living over time.

\section{Recent Strategies}

With these initiatives as VA institutional context and the national governmental focus on prisoner re-entry (Re-entry Policy Council 2005), VA Secretary Nicholson approved the following recommendations of the VA's Mental Health Task Force Strategic Plan (2005):

1. Immediate: Mandate that all VISNs address the transition needs of incarcerated veterans and develop a plan that will be implemented in FY 2005.

2. Future: Each VISN will submit a specific plan for pre-release assessments of veterans in federal and state correctional facilities to determine degree and type of need and methods of providing services. The assessments (are) to include mental health, medical and social service needs (p. A-9).

To address the first recommendation, the VA directed its homeless programs to develop, print, and distribute state-specific re-entry guide books for incarcerated veterans scheduled to be released from prison or jail. A model guide had already been developed by two national organizations and further adapted for Washington State. Each state's homeless program representative was allowed wide latitude to 
develop content but was also held to standards of (a) providing application and access information on state and local agency resources, both VA and non-VA; and (b) identifying basic steps veterans could and should take on their own both in prison and once released to improve their chances of successful community readjustment. The guide books, on average 30 pages in a booklet format, provide information, advice, and resources for application for VA benefits, housing, mental health and substance abuse services, employment, veterans' compensation and pensions, and veterans' service organizations.

The strategy for placing the guides into the hands of soon-to-be-released veteran inmates was developed in 2005 at a meeting of the VA Network Homeless Coordinators in a session with a consultant with corrections experience. Top-down and bottom-up approaches to gaining cooperation and assistance of state Departments of Corrections (DOCs) were set in motion. The newly assigned VA Manager for Homelessness Prevention and Incarcerated Veterans Programs contacted the Association of State Correctional Administrators, the professional organization of the state directors of corrections. He appeared before the directors at their August 2005 national conference to brief them on the VA's incarcerated veterans initiative, and he requested assistance in identifying veterans in their institutions and in distributing the guidebooks to these veterans. With many states under Medicaid budget pressure and eager for community resources to support inmate re-entry, state directors responded to the VA appeal by designating executive DOC staff to contact VA to help with this initiative.

VA Network Homeless Coordinators activated the bottom-up portion of the strategy. They and their staff made contact with prison re-entry and parole staff, and obtained correctional input into guide book content, format, printing specifications, and distribution. Depending on problems encountered, agency priorities, and levels of correctional bureaucracy, this process required 3-6 months to complete. VA coordinators also obtained input from U.S. Department of Labor about veteran state employment resources and from state Departments of Veterans Affairs about veteran resources and benefits outside of the federal Department of Veterans Affairs.

The VA contracted with the Federal Bureau of Prisons to print 1000 guides for each state, totaling 50,000 printed guide books. The printed guide books have been shipped to VA coordinators across the country and are being distributed directly to veterans nearing release through existing outreach service providers, and to Departments of Corrections staff involved in inmate re-entry. Electronic Adobe .pdf versions have also been forwarded to VA coordinators for distribution to correctional and parole staff for use when counseling veterans being released. The guides will be updated annually for changes in resource contact or content information.

Implementing the second recommendation-planning for pre-release assessments-requires three steps. The VA first needed to clearly communicate to Medical Center and outreach staff that outreach services, although not treatment, were within the mission of the VA in supporting community readjustment of veterans. Because VA and HCHV policy had previously supported a limited effort, positive sanctioning of re-entry assessment and planning as well as provision of 
guidance on re-entry services were required to implement a system-wide initiative on incarcerated veterans. This was formally achieved through development and issuance of an Information Letter (Perlin 2006) that clarified the importance of the issue to the VA, and approved and encouraged outreach as part of the pre-release planning process.

The second step is the launching of a formal planning process. All VA VISNs will be directed to develop plans by early 2007 to: (a) establish organizational relationships with state Departments of Corrections and appropriate Federal Bureau of Prisons; (b) develop a model for outreach services to address identified veteran needs; (c) identify pre-release assessment domains and process of assessment; (d) evaluate impact on VA outreach, related VA medical, psychiatric, substance abuse, and homeless services; (e) identify non-VA and other governmental resource capacities; and (f) identify outreach and staff training needs and workload recording and tracking mechanisms. VISNs will activate these plans as the third step of implementation.

Preliminary planning for development of the model has incorporated five principles: (1) encouraging voluntary participation by veterans; (2) coordinating with corrections and non-VA community providers; (3) providing information on VA benefits, including healthcare; (4) screening for medical, social, mental health, and substance abuse problems; and (5) using outreach workers to serve as referral and linkage points of contact upon release as well as follow-up contact for re-entry crises and linkage problems. A November 2006 planning conference attended by VA mental health leadership and clinicians experienced in outreach reviewed and revised this model.

When the actions related to these recommendations are completed, the VA will be positioned to address homelessness prevention to a large at-risk population. The transformation from an informal system serving a few 1000 veterans annually to one that reaches 50,000 veterans through the guide book initiative along with pre-release assessment of re-entering veterans across the state and federal prison systems will constitute a significant systematic national mental health and homelessness prevention endeavor.

\section{Evaluation}

Burt and Pearson (2005) argue that "strong evidence is still lacking that homelessness prevention efforts are effective" and that measuring effectiveness is a critical, but difficult and expensive component of prevention. Their study of six prevention programs found that although the prevention programs were innovative, there was no functional evaluation of the effectiveness of targeting those most at risk or of the housing outcomes. They suggest a more viable evaluation strategy would be to have federal agencies support controlled experiments or quasiexperimental designs.

The premise of the VA prevention strategy for incarcerated veterans is that it targets as many re-entering incarcerated veterans as possible through outreach. With the high prevalence rates of substance abuse, mental illness, and homelessness indicated above, the incarcerated veteran population has high risk for homelessness and for substance abuse, mental illness, and criminal recidivism. 
The VA's evaluation of re-entry prevention services to date has centered on two initiatives, one national and one local, that are assessing the effectiveness of outreach efforts in linking veterans to VA services. Nationally, VA and DOL have collected data on the effectiveness of employment and outreach services in the IVTP project. Preliminary evaluation data on 333 released veterans who were provided services through IVTP showed that $57 \%$ were linked to the VA for services in the year after their release. The Department of Labor is evaluating the employment service and outcomes segment of the IVTP project, domains that are expected to play an important role in the prevention of homelessness. In the second VA study of 1,676 veterans receiving outreach services at the Los Angeles County jail, researchers found that $38 \%$ of veterans were linked to VA services, less than one-half the rate $(84 \%)$ of homeless veterans in the community (McGuire et al. 2003). Though levels of health care problems differed for the two groups, there were clearly service needs in which the veterans from jail were disadvantaged: Veterans from the jail had fewer physical health problems, but they had more psychiatric and substance abuse problems and were much less likely to use (30\% vs. $73 \%)$ VA mental health services than the veterans from the community. Both studies are continuing to evaluate follow-up use of mental health and substance abuse services, and criminal justice involvement through examination of administrative records, but neither study is examining housing outcomes, which involves costly follow-up interview evaluation methodology.

VA's guide book and pre-release assessment strategies will also be evaluated for effectiveness in preventing homelessness. One VA homeless program site has begun conducting a pilot evaluation in collaboration with the state's Department of Corrections to study the impact of the guides on subsequent VA services use and housing. Once the pre-release assessment initiative is operational, the VA will be able to build on the experience of this pilot and compare the two prevention approaches.

\section{Discussion}

This paper has described the VA's homelessness prevention initiative for incarcerated veterans including the population's risk characteristics, and the evolution and current status of prevention and evaluation strategies. Although the level of risk for homelessness has not been determined for incarcerated veterans, research suggests a strong link exists between incarceration and homelessness for veterans. The population's risk is further compounded by high rates of substance abuse and mental illness. VA's strategy to lower homelessness risk in this group is a multi-pronged services initiative that has contacted large numbers of re-entering veterans, many of whom become subsequent users of VA services that can be expected to reduce risk. This prevention strategy is in process of major expansion through systematic education of re-entering incarcerated veterans about services available to them and the veterans' role in re-entry, and through a system-wide outreach initiative to assess and link these veterans to services they need. 
Though years in the making, the VA initiative is still a model under development. As an organized program addressing an at-risk population that is designed to reduce the rate of new cases of homelessness, the VA initiative meets the criteria for public health prevention (Caplan and Caplan 2000). From the perspective of crisis theory, an important foundation of prevention in mental health services, re-entry can be viewed as a potentially hazardous transition. Caplan and Caplan emphasize the need for: psychosocial support to reduce negative emotional tension during transitions; guidance regarding the hazardous transition and how to master it; money, concrete goods, and services; and action on the part of the person at risk. The VA's model incorporates all of these components.

VA's resources and services can provide potent supports for re-entry transition. Upon release, veterans who qualify for $100 \%$ Service-connected compensation can receive $\$ 2,393$ per month, or up to $\$ 881$ per month if they qualify for a non-service connected pension. High quality VA medical care is available as well. According to a recent RAND study, the quality of VA services across a spectrum of 294 measures of quality in disease prevention and treatment outperformed all other sectors of American health care (Asch et al. 2004). VA's transitional residential rehabilitation services are extensive: (a) VA's Grant and Per Diem program nationally funds almost 10,000 housing beds through community agencies; (b) VA's Domiciliary program funds 7,000 beds; and (c) VA's Psychosocial Residential Rehabilitation Treatment Program funds 1,800 beds. A U.S. Government Accountability Office report cited a recent study of VA transitional housing services that found that $83 \%$ of the veterans were independently housed or living with friends or family 1 year following discharge from VA-funded transitional housing programs (U.S. Government Accountability Office 2006a). VA's Mental Health Service has made a significant commitment to supported employment and to implementing mental health recovery concepts and peer support. VA clinical staff assist veterans with coordination of medical, mental health and substance abuse treatment, vocational, housing, dental, income, and case management services as needed. No other system is able to address the types and quality of services needed by re-entering inmates as they try to make the best of a new chance at living successfully in the community.

The VA health care system and its homelessness prevention initiative do have limitations. Although enhancement funding (U.S. Government Accountability Office 2006b) is currently increasing VA's capacity to expand mental health services, this prevention initiative is likely to further increase demand for mental health and substance abuse services. VA's mission does not include authority for the permanent housing services that these veterans will need. Coordinating the multiple services these veterans may need is very difficult in a large bureaucratic health care system.

The homelessness prevention initiative's targeting efficiency has not been evaluated: Is a strategy that provides outreach to as many incarcerated veterans as possible - a population at risk for homelessness, substance abuse, mental illness, unemployment, and criminal recidivism-inefficient for the prevention of homelessness? Ethically, can targeting efficiency even be tested (Uhl 2000)? Neither VA study of outreach effectiveness to incarcerated veterans has collected follow-up data on housing. Neither has data been collected to specify which 
interventions-information, outreach, referral, etc.-are effective for specific veteran social and clinical outcomes.

The fact that the VA's homelessness prevention strategy is embedded in the overall incarcerated veterans' program suggests there may be difficulty in maintaining focus on this particular aspect of the re-entry program. In order not to lose sight of the goal of preventing homelessness, Leginski and Randolph (1999) argue that "careful conceptualization and relevant data are our best analytic defenses" in implementing large systems initiatives (p. 1257). Others have demonstrated the utility of 'logic modeling' for implementation evaluation, a technique that structures review of links between program assumptions, client needs and outcomes, program resources, and data collection (Morzinskis and Montagnini 2002; Mulroy and Lauber 2004). VA's pre-release planning directive will provide a point of entry for incorporation and assessment of these domains, and a roadmap for evaluation that improves assessment of prevention outcomes through longitudinal studies.

In summary, the VA's experience suggests that incarcerated veterans are suitable targets for prevention of homelessness and VA services fit well with their needs as they exit correctional institutions. If VA's system-wide initiative is carefully implemented and evaluated, re-entering veterans are likely to have higher probability of successful community re-adjustment housing outcomes, and VA will be able to provide the widest possible prevention coverage to those most in need of the appropriate elements of VA's service package.

Acknowledgment The author would like to acknowledge VA administrators and clinicians whose leadership, work, and passion have laid the foundation for the expansion of re-entry services for incarcerated veterans nationwide.

\section{References}

Asch, S. M., McGlynn, E. A., Hogan, M. M., Hayward, R. A., Shekelle, P., \& Rubenstein, L., et al. (2004). Comparison of quality of care for patients in the Veterans Health Administration and patients in a national sample. Annals of Internal Medicine, 141, 938-945.

Burt, M. R. (2001). What will it take to end homelessness? Washington, DC: The Urban Institute.

Burt, M. R., Aron, L. Y., Douglas, T., Valente, J., Lee, E., \& Iwen, B. (1999). Homelessness: Programs and the people they serve. Summary report. Findings of the National Survey of Homeless Assistance Providers and Clients. Washington, DC: The Urban Institute.

Burt, M. R., \& Pearson, C. L. (2005). Strategies for preventing homelessness. Washington, DC: U.S. Department of Housing and Urban Development, Office of Policy Development and Research.

California Department of Corrections. (1997). Preventing Parolee Failure Program: An evaluation. Sacramento, CA: State of California Department of Corrections.

Caplan, G., \& Caplan, R. B. (2000). The future of primary prevention. The Journal of Primary Prevention, 21, 131-135.

Caton, C. L., Dominguez, B., Schanzer, B., Hasin, D. S., Shrout, P. E., \& Felix, A., et al. (2005). Risk factors for long-term homelessness: Findings from a longitudinal study of first-time homeless single adults. American Journal of Public Health, 95, 1753-1759.

Douyon, R., Guzman, P., Romain, G., Ireland, S. J., Mendoza, L., \& Lopez-Blanco, M., et al. (1998). Subtle neurological deficits and psychopathological findings in substance-abusing homeless and non-homeless veterans. The Journal of Neuropsychiatry and Clinical Neurosciences, 10, 210-215.

Fischer, P. J. (1988). Criminal activity among the homeless: A study of arrests in Baltimore. Hospital and Community Psychiatry, 39, 46-51. 
Gamache, G., Rosenheck, R., \& Tessler, R. (2001). The proportion of veterans among homeless men: A decade later. Social Psychiatry and Psychiatric Epidemiology, 36, 481-485.

Kasprow, W. J., Rosenheck, R., DiLella, D., Cavallaro, L., \& Harelik, N. (2003). Health Care for Homeless Veterans Programs: The sixteenth annual report. West Haven, CT: Department of Veterans Affairs Northeast Program Evaluation Center.

Kasprow, W. J., Rosenheck, R., DiLella, D., Cavallaro, L., \& Harelik, N. (2004). Health Care for Homeless Veterans Programs: The seventeenth annual report. West Haven, CT: Department of Veterans Affairs Northeast Program Evaluation Center.

Kasprow, W. J., Rosenheck, R., DiLella, D., Cavallaro, L., \& Harelik, N. (2005). Health Care for Homeless Veterans Programs: The eighteenth annual report. West Haven, CT: Department of Veterans Affairs Northeast Program Evaluation Center.

Kasprow, W. J., Rosenheck, R., DiLella, D., Cavallaro, L., \& Harelik, N. (2006). Health Care for Homeless Veterans Programs: The nineteenth annual report. West Haven, CT: Department of Veterans Affairs Northeast Program Evaluation Center.

Langan, P. A., \& Levin, D. J. (2002). Recidivism of prisoners released in 1994 [Rep. No. NCJ 193427]. Washington, DC: U.S. Department of Justice, Bureau of Justice Statistics.

Leginski, W., \& Randolph, F. (1999). How well are we evaluating system change? Psychiatric Services, $50,1257$.

Lezak, A. D., \& Edgar, E. (1996). Preventing homelessness among people with serious mental illness. Rockville, MD: U.S. Department of Health and Human Services Center for Mental Health Services.

Lindblom, E. N. (1991). Toward a comprehensive homelessness-prevention strategy. Housing Policy Debate, 2, 957-1025.

Mares, A. S., \& Rosenheck, R. A. (2004). Perceived relationship between military service and homelessness among homeless veterans with mental illness. The Journal of Nervous and Mental Disease, 192, 715-719.

McGuire, J. F., Rosenheck, R. A., \& Kasprow, W. J. (2003). Health status, service use, and costs among veterans receiving outreach services in jail or community settings. Psychiatric Services, 54, 201-207.

Metraux, S., \& Culhane, D. P. (2004). Homeless shelter use and reincarceration following prison release. Criminology and Public Policy, 3, 139-160.

Morzinskis, J. A., \& Montagnini, M. L. (2002). Logic modeling: A tool for improving educational programs. Journal of Palliative Medicine, 5, 566-570.

Mulroy, E. A., \& Lauber, H. (2004). A user-friendly approach to program evaluation and effective community interventions for families at risk for homelessness. Social Work, 49, 573-586.

Mumola, C. J. (2000). Veterans in prison or jail [Rep. No. NCJ 178888]. Washington, DC: U.S. Department of Justice Office of Justice Programs.

National Alliance to End Homelessness. (2000). A plan: Not a dream. How to end homelessness in ten years. Retrieved February 15, 2007, from http://www.endhomelessness.org/content/article/detail/ $585 /$

Perlin, J. B. (2006). VHA Information Letter 10-2006-007. Guidelines and recommendations for services provided by VHA facilities to incarcerated veterans re-entering community living. Washington, DC: U.S. Department of Veterans Affairs.

Re-entry Policy Council. (2005). Report of the Re-entry Policy Council: Charting the safe and successful return of prisoners to the community. New York: Council of State Governments.

Rosenheck, R., Bassuk, E., \& Salomon, A. (1999). Special populations of homeless Americans. In L. B. Fosburg, \& D. L. Dennis (Eds.), Practical lessons: The 1998 National Symposium on Homelessness Research. Washington, DC: U.S. Department of Housing and Urban Development.

Rosenheck, R. A., \& Koegel, P. (1993). Characteristics of veterans and nonveterans in three samples of homeless men. Hospital and Community Psychiatry, 44, 858-863.

Uhl, A. (2000). The future of primary prevention. The Journal of Primary Prevention, 21, 43-45.

U.S. Department of Veterans Affairs Office of Public Affairs. (2006). Federal benefits for veterans and dependents, 2006 edition. Washington, DC: U.S. Government Printing Office.

U.S. Government Accountability Office. (2006a). Homeless veterans programs: Improved communications and follow-up could further enhance the grant and per diem program [Rep. No. GAO-06-859]. Washington, DC: U.S. Government Accountability Office.

U.S. Government Accountability Office. (2006b). VA health care: Preliminary information on resources allocated for mental health strategic plan initiatives [Rep. No. GAO-06-1119T]. Washington, DC: U.S. Government Accountability Office. 
VA Mental Health Task Force (2005). The comprehensive VHA mental health strategic plan. Washington, DC: U.S. Department of Veterans Affairs.

Wenzel, S. L., Gelberg, L., Bakhtiar, L., Caskey, N., Hardie, E., \& Redford, C., et al. (1993). Indicators of chronic homelessness among veterans. Hospital and Community Psychiatry, 44, 1172-1176. 